\title{
Prevalência de anticorpos e fatores de risco associados à infecção por Toxoplasma gondii em galinhas domésticas da zona rural de Santa Maria, Rio Grande do Sul ${ }^{1}$
}

\author{
Giovana Camillo ${ }^{2 *}$, Marta E.A. Machado², Augusto Weber², Gustavo C. Cadore², \\ Fernanda R. Menezes ${ }^{3}$, Lais Pardini ${ }^{4}$, Luis A. Sangioni ${ }^{2}$ e Fernanda S.F. Vogel ${ }^{2}$
}

\begin{abstract}
Camillo G., Machado M.E.A., Weber A., Cadore G.C., Menezes F.R., Pardini L., Sangioni L.A. \& Vogel F.S.F. 2018. [Prevalence of antibodies and risk factors associated with infection by Toxoplasma gondii in free range chickens of rural area of Santa Maria, Rio Grande do Sul, Brazil.] Prevalência de anticorpos e fatores de risco associados à infecção por Toxoplasma gondii em galinhas domésticas de zona rural de Santa Maria, Rio Grande do Sul. Pesquisa Veterinária Brasileira 38(7):1351-1357. Laboratório de Doenças Parasitárias, Universidade Federal de Santa Maria, Av. Roraima 1000, Santa Maria, RS 97105-900, Brazil. E-mail: giovanacamillo@yahoo.com.br

Toxoplasma gondii is an apicomplex protozoan that infects warm-blooded animals and can be considered a major parasite capable of infecting humans. Domestic chickens can be easily infected by protozoa, since they can ingest oocysts found in the soil and are considered good indicators of environmental contamination by T. gondii. The aim of this study was to determine the presence of anti-T. gondii antibodies in free range chickens and to evaluate the risks factors associated with the protozoan in rural area of Santa Maria, RS, Brazil. From March 2013 to February 2014, 597 blood samples from domestic chickens were collected from 74 farms, from nine layers representing each district in the rural area. To evaluate the risk factors, in these farms an epidemiological questionnaire was applied to the residents. Serum samples were tested by indirect immunofluorescence and $49.2 \%$ (294/597) were positive for anti-T.gondii antibodies, with titres varying from 16 to 4096. Of the 74 analyzed farms, $63(85.1 \%)$ reported that cats had access to food deposits, with a significant association when positive chickens were present $(\mathrm{p}=0.04)$ and the OR of 4.07. The variable "slaughter of animals" (poultry and cattle) in 51 (68.9\%) of the farms was reported the slaughter of cattle and birds in the farm, with significant $p$ value $(p=0.05)$. Most farms $59(79.7 \%)$ reported the presence of domestic cats, which could be associated with the high seroprevalence found in chickens and the rate of environmental contamination. The high prevalence of antibodies found in this study, in addition to the high frequency of farms with positive cases, suggests a great environmental contamination in the studied districts, thus being a potential risk to human and animal health.
\end{abstract}

INDEX TERMS: Antibodies, risk factor, infection, Toxoplasma gondii, toxoplasmosis, free range, chickens, rural area, indirect fluorescent test, environmental contamination, IgY, Gallus gallus domesticus, Rio Grande do Sul, parasitoses.

\footnotetext{
${ }^{1}$ Recebido em 25 de setembro de 2017.

Aceito para publicação em 8 de janeiro de 2018.

2 Departamento de Medicina Veterinária Preventiva (DMVP), Centro de Ciências Rurais (CCR), Universidade Federal de Santa Maria (UFSM), Santa Maria, RS 97105-900, Brasil. *Autor para correspondência: giovanacamillo@yahoo.com.br

${ }^{3}$ Programa de Pós-Graduação em Economia e Desenvolvimento (PPGED), Universidade Federal de Santa Maria, Santa Maria, RS 97105-900.

${ }^{4}$ Laboratório de Imunoparasitologia, Universidade Nacional de La Plata, Calle 51 entre 124 y 125 s/n, 1925 La Plata, Buenos Aires, Argentina.
}

RESUMO-- Toxoplasma gondii é um protozoário apicomplexa que infecta animais de sangue quente, podendo ser considerado um dos principais parasitas capazes de infectar os seres humanos. Galinhas domésticas podem ser facilmente infectadas por protozoários, uma vez que estas podem ingerir oocistos encontrados no solo, sendo consideradas boas indicadoras de contaminação ambiental por T. gondii. O objetivo deste estudo foi determinar a presença de anticorpos anti-T. gondii em galinhas domésticas criadas extensivamente e avaliar os 
fatores de risco associados ao protozoário, na zona rural de Santa Maria, RS, Brasil. No período de março de 2013 a fevereiro 2014 foram coletadas 597 amostras de sangue de galinhas domésticas em 74 propriedades, oriundas de nove estratos que representam cada distrito da zona rural. Para avaliar os fatores de risco, nessas propriedades foi aplicado um questionário epidemiológico aos moradores. As amostras de soro foram testadas por imunofluorescência indireta, e 49,2\% (294/597) foram positivas para anticorpos anti-T. gondii, com títulos variando de 16 a 4096. Das 74 propriedades analisadas, em $63(85,1 \%)$ houve relatos que os gatos têm acesso ao deposito de alimentos, com associação significativa quando associado à presença de galinhas positivas $(p=0,04)$ e o OR de 4,07. A variável "abate de animais" (aves e bovinos), em $51(68,9 \%)$ das propriedades foi relatado o abate de bovinos e aves na propriedade, com valor de $p$ significativo $(p=0,05)$. A maioria das propriedades $59(79,7 \%)$ foi relatada a presença de gatos domésticos, o que poderia estar associada com a alta soroprevalência encontrada em galinhas e a taxa de contaminação ambiental. A elevada prevalência de anticorpos encontrada neste estudo, além da alta frequência de propriedades com casos positivos, sugere uma grande contaminação ambiental nos distritos pesquisados, sendo assim um risco potencial para a saúde humana e animal.

TERMOS DE INDEXAÇÃO: Anticorpos, fatores de risco, infecção, Toxoplasma gondii, galinhas domésticas, zona rural, toxoplasmose, teste de imunofluorescência indireta, contaminação ambiental, IgY, Gallus gallus domesticus, Santa Maria, Rio Grande do Sul, parasitoses.

\section{INTRODUÇÃO}

Toxoplasma gondii é um protozoário intracelular obrigatório, zoonótico, capaz de infectar mamíferos e aves (Tenter et al. 2000). Sua infecção é prevalente em várias espécies de aves, podendo causar mortalidade nestes animais (Dubey et al. 2010a). Felídeos são os únicos hospedeiros definitivos do T. gondii, podendo excretar oocistos no meio ambiente, que servem como fonte de infecção para outros animais (Dubey 2002). Galinhas domésticas (Gallus gallus domesticus) são consideradas importantes hospedeiros intermediários deste protozoário, pois se infectam através da ingestão de oocistos excretados nas fezes de felinos infectados (Ruiz \& Frenkel 1980). Assim, estas aves têm grande potencial à exposição aos oocistos esporulados, uma vez que as mesmas são criadas em condições extensivas, tendo contato com o solo, podendo servir como indicadores de contaminação ambiental. As galinhas domésticas atuam também como eficiente fonte de infecção do T. gondii para gatos e humanos, que podem se infectar após a ingestão de carne crua ou mal cozida, contendo as formas infectantes do parasito (Dubey 2002, Dubey et al. 2010a).

Em áreas rurais, a distribuição da infecção através dos oocistos pode variar amplamente em decorrência de diversos fatores como a distância entre as casas, o tipo de exploração agropecuária e o cultivo de hortas. As condições ambientais, hábitos culturais e a própria fauna constituem alguns dos fatores que podem explicar a variabilidade desta infecção em diferentes áreas geográficas de um determinado país (Tenter et al. 2000). 0 impacto da contaminação por oocistos na epidemiologia necessita ser avaliado, pois pode estar diretamente relacionado a altas taxas de infecções em animais e humanos (Tenter et al. 2000, Bahia-Oliveira et al. 2003).
No Brasil, estudos pesquisando a presença de anticorpos em galinhas de criação extensiva, utilizando teste de aglutinação modificado (MAT) e reação de imunofluorescência indireta (RIFI) como técnicas sorológicas, detectaram valores de ocorrência altamente variáveis ao T. gondii (Dubey et al. 2012). Embora este protozoário seja de grande importância e bastante estudado, ainda existem poucos estudos epidemiológicos, principalmente no estado do Rio Grande do Sul. Diante desta perspectiva, o presente estudo teve como objetivo determinar a presença de anticorpos anti-T. gondii em galinhas domésticas na cidade de Santa Maria, no estado Rio Grande do Sul, Brasil, e também correlacionar os principais fatores de risco em propriedades na zona rural desta cidade.

\section{MATERIAL E MÉTODOS}

O estudo foi realizado em propriedades da zona rural do município de Santa Maria, na região central do estado do Rio Grande do Sul, Brasil. O município possui uma área rural de 144.054 hectares, dividida em nove localidades, denominados distritos. Para a estimativa da amostragem de propriedades foram utilizados dados oficiais, obtidos na Secretaria da Agricultura, Pecuária e Irrigação do Rio Grande Sul (Seapi/RS). A partir desses dados determinou-se a amostragem, de forma estratificada proporcional, com $90 \%$ de confiança, representado por 74 propriedades. A escolha das propriedades foi de forma aleatória, considerando os nove estratos, os quais representavam cada distrito da zona rural de Santa Maria.

As propriedades da amostragem foram visitadas entre março de 2013 a fevereiro 2014. Inicialmente foi aplicado um questionário epidemiológico para avaliar os fatores de risco referentes a hábitos higiênico-alimentares, espécies animais criadas na propriedade e conhecimento sobre a toxoplasmose. Ao término, foram distribuídos folhetos educativos com medidas de prevenção para a infecção.

Em cada propriedade, foram coletadas amostras de sangue de 10 galinhas. Aquelas propriedades nas quais o total de galinhas era inferior a 10, coletava-se todas, o que totalizou 597 galinhas adultas criadas de forma extensiva. 0 sangue foi coletado por punção da veia ulnar, centrifugado por 10 minutos a $1600 x g$, para obtenção do soro, que foi armazenado a $20^{\circ} \mathrm{C}$ negativos até sua utilização. A detecção de anticorpos anti-Toxoplasma gondii foi realizado através de técnica de imunofluorescência indireta (RIFI), com taquizoítos da cepa RH de T. gondii, utilizado como antígeno para detecção de imunoglobulina Y (IgY) anti-T. gondii. Foi utilizado como anticorpo secundário Anti-chicken IgY ${ }^{\oplus 5}$ conjugado com fluoresceína, conforme a técnica realizada por Moré et al. (2008). Amostras sabidamente positivas e negativas, foram utilizadas como controles. Todas as amostras de soro positivas na diluição de 1:16 foram consideradas positivas (Garcia et al. 2000) sendo submetidas às demais diluições para determinação do título máximo da reação.

Para análise dos fatores de risco, as variáveis contidas no questionário investigativo aplicado aos moradores foram analisadas através do programa Epinfo 6.0 e submetidas ao teste Qui-quadrado. Com o objetivo de pesquisar a associação entre as diversas variáveis, foi calculada a força das associações mediante o cálculo do (OR) odds ratio e seus respectivos intervalos de confiança de $95 \%(p<0,05)$. A freqüência de propriedades com galinhas soropositivas em cada distrito foi comparada pelo Teste de qui-quadrado, com $90 \%$ de confiança.

\footnotetext{
5 Anti-chicken $\operatorname{IgY}{ }^{\odot}$ conjugada com a fluoresceína (FITC): Affinity Purified Antibody Fluorescein. Sigma, St Louis, MO, USA.
} 


\section{RESULTADOS}

Das 597 amostras de soro de galinhas analisadas, 294 (49,2\%) foram positivas para anticorpos anti-Toxoplasma gondii. As amostras de soro positivas foram submetidas à titulação e os títulos de anticorpos variaram de 16 a 4096 (Quadro 1). Em relação às propriedades analisadas, pode-se verificar que a maioria destas $(94,6 \%)$ apresentava pelo menos uma galinha positiva. Em quatro $(5,4 \%)$ propriedades avaliadas, não foram encontrados animais anticorpo positivo. Houve uma elevada prevalência de anticorpos anti-T. gondii em todos os nove distritos analisados, indicando elevada contaminação ambiental nesses locais. A prevalência de anticorpos anti-T. gondii foi significativamente menor $(\mathrm{p}=0,051)$ no distrito de Arroio do Só, sugerindo uma menor contaminação ambiental nesse local.
Através da análise univariada dos fatores de risco à infecção por T. gondii nas 74 propriedades avaliadas, pode-se observar que em 63 locais $(85,1 \%)$ há relatos que os gatos têm acesso ao depósito de alimentos, com associação significativa quando relacionado à presença de galinhas positivas $(p=0,04)$ e o OR de 4,07. Conforme relato de proprietários, esses gatos são criados com a finalidade de combater os roedores que buscam alimentos nos depósitos, o que também poderia estar relacionado com a contaminação destes ambientes. Quando avaliada a variável abate de animais, das 74 propriedades, em $51(68,9 \%)$ foi relatado o abate de bovinos e aves para consumo, com valor de $p$ significativo $(p=0,05)$. A utilização de água de mina ou vertentes para abastecimento animal apresentou influência significativa quando associado a galinhas soropositivas $(p<0,05)$, o OR de 0,15 , mas um intervalo de confiança não significativo (Quadros 2 e 3).

Quadro 1. Frequência de anticorpos anti-Toxoplasma gondii detectados através da reação de imunofluorescência indireta em galinhas criadas extensivamente em nove distritos da zona rural de Santa Maria/RS, de março 2013 a fevereiro 2014

\begin{tabular}{|c|c|c|c|c|c|c|c|c|c|c|c|}
\hline \multirow{2}{*}{$\begin{array}{c}\text { Distrito } \\
\text { (nº de propriedades) }\end{array}$} & & \multicolumn{9}{|c|}{ Título de anticorpos } & \multirow{2}{*}{ № galinhas positivas/total (\%) } \\
\hline & & 16 & 32 & 64 & 128 & 256 & 512 & 1024 & 2048 & 4096 & \\
\hline Passo do Verde (4) & $\mathrm{N}$ & 1 & 1 & 10 & 9 & 6 & 3 & 0 & 0 & 0 & $30 / 36(83,3)$ \\
\hline São Valentim (5) & $\mathrm{N}$ & 0 & 1 & 7 & 10 & 6 & 1 & 0 & 0 & 0 & $25 / 38(65,8)$ \\
\hline Pains (9) & $\mathrm{N}$ & 14 & 9 & 2 & 2 & 0 & 3 & 2 & 9 & 3 & $44 / 72(61,1)$ \\
\hline Santa Flora (11) & $\mathrm{N}$ & 11 & 6 & 12 & 1 & 10 & 5 & 0 & 5 & 5 & $55 / 97(56,7)$ \\
\hline Boca do Monte (17) & $\mathrm{N}$ & 15 & 9 & 15 & 6 & 8 & 2 & 0 & 0 & 0 & $55 / 127(43,3)$ \\
\hline Arroio Grande (12) & $\mathrm{N}$ & 11 & 7 & 6 & 6 & 4 & 4 & 1 & 4 & 1 & $44 / 102(43,1)$ \\
\hline Palma (6) & $\mathrm{N}$ & 3 & 1 & 5 & 3 & 0 & 3 & 3 & 2 & 0 & $20 / 60(33,3)$ \\
\hline Arroio do Só (5) & $\mathrm{N}$ & 1 & 2 & 2 & 3 & 1 & 0 & 0 & 0 & 0 & $9 / 27(33,3)$ \\
\hline Santo Antão (5) & $\mathrm{N}$ & 0 & 4 & 2 & 3 & 1 & 1 & 1 & 0 & 0 & $12 / 38(31,5)$ \\
\hline TOTAL & $\mathrm{N}$ & 56 & 40 & 61 & 43 & 36 & 22 & 7 & 20 & 9 & $294 / 597(49,2)$ \\
\hline
\end{tabular}

$\overline{\mathrm{N}}=$ Número de galinhas.

Quadro 2. Análise univariada para os fatores de risco relacionados a humanos, associados ou não à soropositividade para Toxoplasma gondii, em galinhas criadas extensivamente em propriedades da zona rural de Santa Maria/RS, de março 2013 a fevereiro 2014

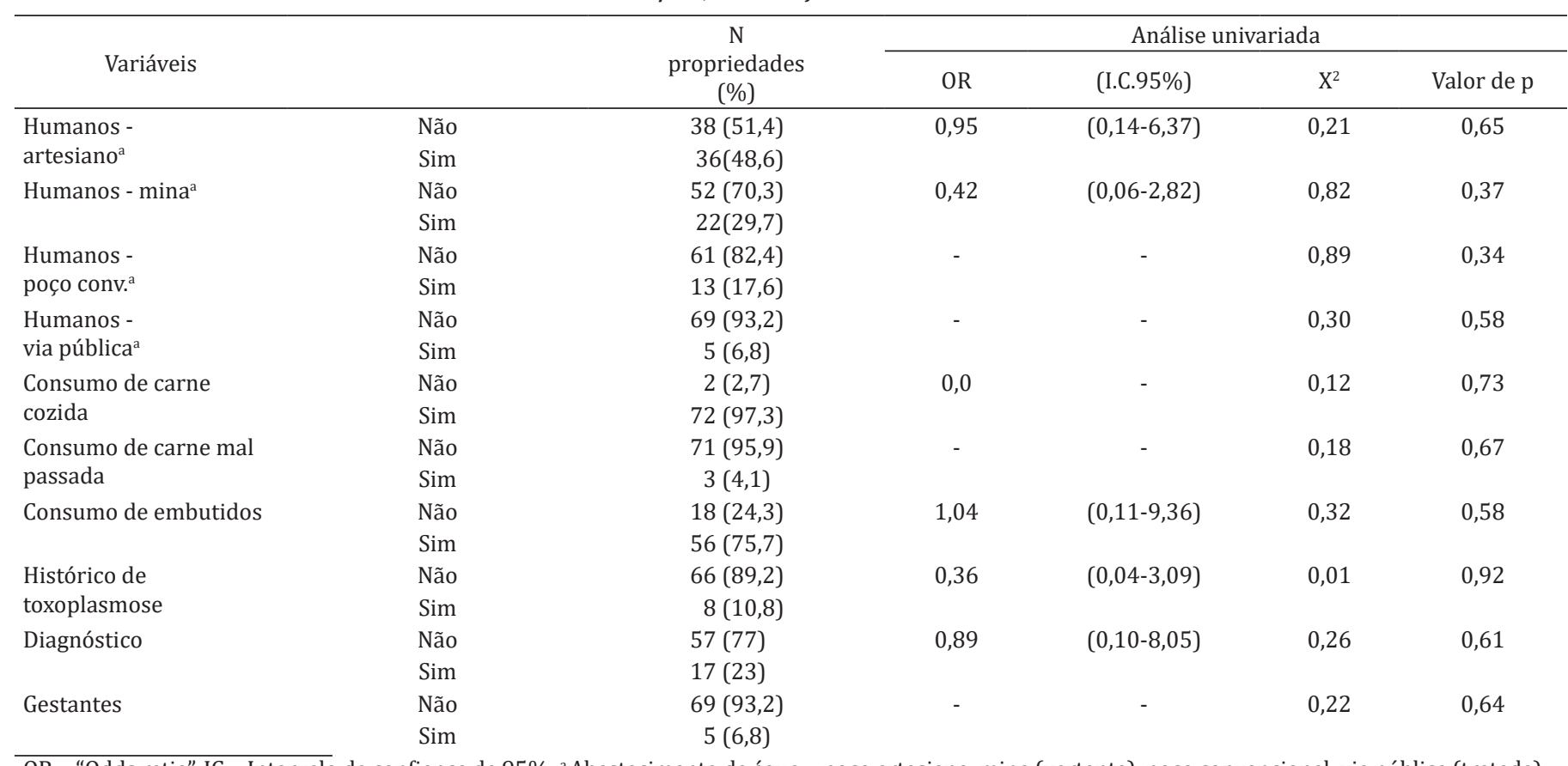

$\overline{\mathrm{OR}}=$ “Odds ratio", IC = Intervalo de confiança de 95\%; a Abastecimento de água = poço artesiano, mina (vertente), poço convencional, via pública (tratada). 
Quadro 3. Análise univariada para os fatores de risco relacionados aos animais, associados ou não à soropositividade para T. gondii em galinhas galinhas criadas extensivamente em propriedades da zona rural do município de Santa Maria/RS, de março de 2013 a fevereiro de 2014

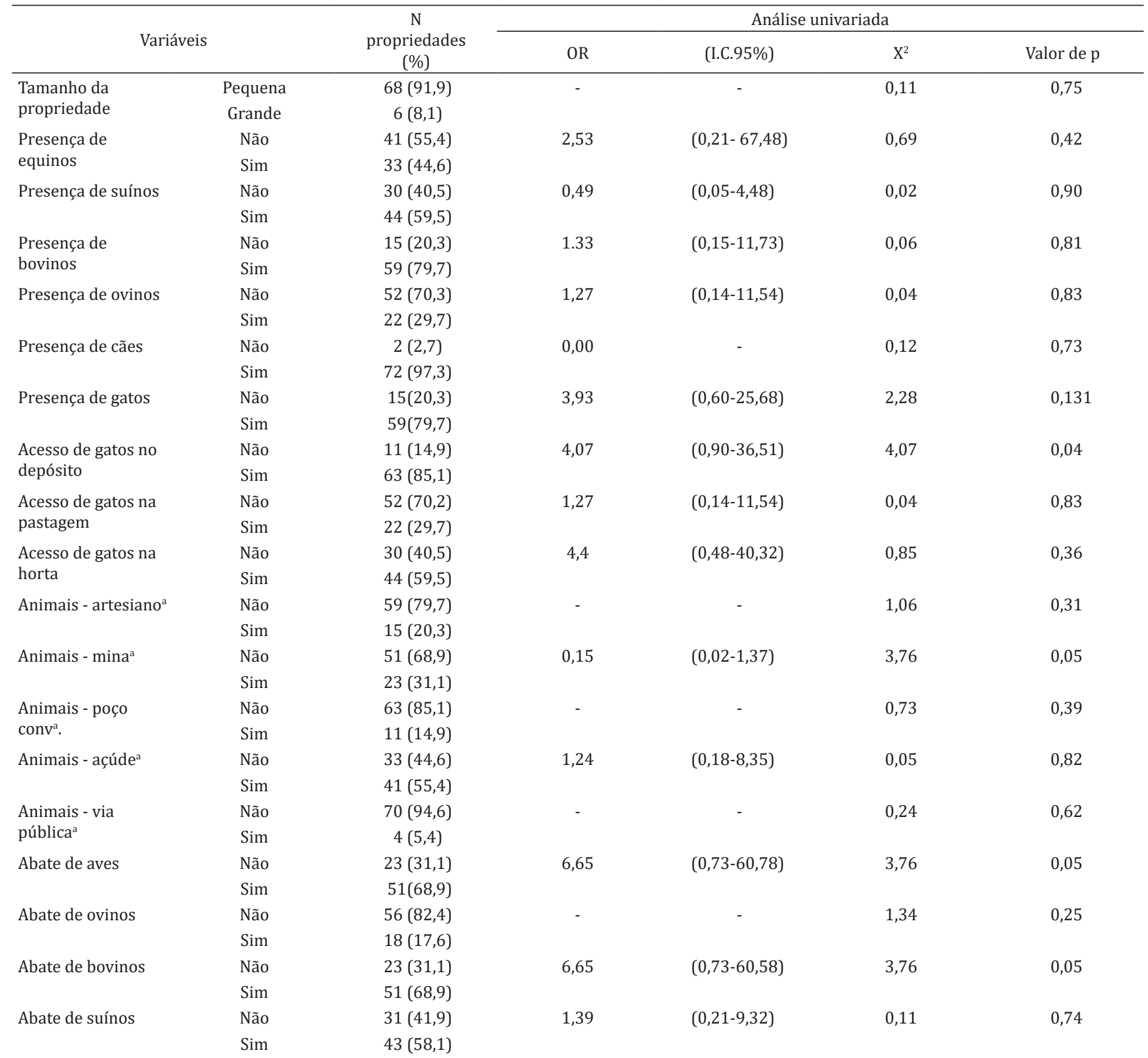

OR = “Odds ratio”, IC = Intervalo de confiança de 95\%, Depósito = local de armazenamento de alimentos dos animais, Número de gatos = 59 propriedades afirmaram ter gatos na residência e 63 afirmaram que esses gatos têm acesso ao depósito de alimento, tendo também circulação de gatos de propriedades vizinhas, nesses locais; ${ }^{a}$ Abastecimento de água = poço artesiano, mina (vertente) e poço convencional (não tratadas), via pública (tratada).

\section{DISCUSSÃO}

Os resultados encontrados no presente trabalho demonstram uma grande prevalência de galinhas anticorpo positivas para o protozoário Toxoplasma gondii. Estudos realizados no Brasil demonstram diferentes percentuais de galinhas domésticas positivas ao T. gondii. Alguns relatam uma taxa de detecção de anticorpos superior à encontrada no presente estudo (49,2\%), como em Rondônia, com 66\% (Dubey et al. 2006) e em Fernando de Noronha, com 84\% de animais positivos (Dubey et al. 2010b). Outros trabalhos relatam frequências semelhantes, no Nordeste de 53,3\% (Oliveira et al. 2009), Minas Gerais com 53,6\% (Brandão et al. 2006) e também índices inferiores, como de 38,8\% no Espírito Santo (Beltrame et al. 2012), 27,6\% no Rio de Janeiro (Casartelli-Alves et al. 2012) e de $10,3 \%$ no estado do Paraná (Garcia et al. 2000). No Rio Grande do Sul, a pesquisa mais recente foi realizada na 
região sul, com uma ocorrência de anticorpos anti-T. gondii em 38\% das galinhas pesquisadas (Dubey et al. 2007). É importante destacar que as técnicas utilizadas nesses estudos podem ter influenciado nos diferentes resultados obtidos. Nos estudos acima mencionados, a maioria os autores usaram a técnica de aglutinação modificada (MAT), sendo a mesma considerada mais acurada, conforme (Casartelli-Alves et al. 2014, Dubey et al. 2016). A técnica de imunofluorescência indireta (IFI), realizada no presente estudo também é utilizada com frequência em diferentes estudos, porém apresenta alta sensibilidade e baixa especificidade (Casartelli-Alves et al. 2014).

Os dados de sorologia apresentados demonstram a ampla distribuição deste protozoário em diferentes regiões do Brasil. Ressalta-se que, conforme observado por Casartelli-Alves et al. (2012), a maioria destes trabalhos são de detecção de anticorpos e não da estimativa de prevalência e fatores de risco. Muitos destes estudos foram desenvolvidos com intuito de determinar a diversidade genética do T. gondii, não se preocupando com cálculo amostral e sorteio aleatório das propriedades. Desta forma, o planejamento amostral do presente estudo, torna os resultados sorológicos obtidos $(49,2 \%)$ de grande importância epidemiológica e de alta confiabilidade, considerando a representatividade da amostragem.

Com relação aos títulos de anticorpos anti-T. gondii encontrados, os fatores que podem influenciar a variação dos mesmos podem estar relacionados com características de patogenicidade e virulência do agente ou da dose infectante, assim como observado por Larsson (1989). Nos títulos de anticorpos obtidos em cada localidade, os maiores títulos (2048 e 4096) foram observados em três distritos - Arroio Grande, Pains e Santa Flora, podendo assim, sugerir uma infecção aguda ou reinfecção por T. gondii, demonstrando que os títulos podem estar relacionados com o tempo de infecção (Wastling et al. 1995, Dzitko et al. 2006).

A pesquisa de anticorpos anti-T. gondii em galinhas criadas extensivamente é de grande importância, uma vez que essas aves atuam como boas indicadoras da contaminação por oocistos de T. gondi no ambiente. Conforme Dubey (2010a), a detecção direta dos mesmos no solo é considerada de difícil diagnóstico e impraticável, o que torna a estimativa da taxa de contaminação ambiental por oocistos, a partir da sorologia de galinhas, uma importante ferramenta epidemiológica. Dessa forma, a alta prevalência de anticorpos anti-T. gondii em galinhas dos nove distritos estudados e o alto número de propriedades com galinhas positivas indicam elevada contaminação ambiental em todos os distritos estudados do município de Santa Maria, o que denota os altos riscos para a saúde humana e animal.

Estudos já relataram que a presença de gatos pode ser o principal fator de risco para T. gondii, já que animais podem se infectar ao ingerirem alimentos eágua contaminados com oocistos liberados nas fezes de felinos infectados (Luzon et al. 1997). No presente estudo, na maioria das propriedades $59(79,7 \%)$ foi relatada a presença de gatos domésticos, o que poderia estar associada com a alta soroprevalência encontrada em galinhas e a taxa de contaminação ambiental. Das 15 (20,3\%) propriedades que relataram não ter gatos, apenas em duas não foram encontradas galinhas anticorpo positivas para T.gondii. Isto pode ser explicado pela sobrevivência dos oocistos no solo, que pode ser de até 18 meses (Dubey 1998) ou pelo hábito que os gatos têm de percorrer quilômetros para caçar ou até mesmo em busca de fêmeas no cio, facilitando a disseminação de oocistos nas propriedades. No entanto, a análise estatística realizada na amostra em estudo não evidenciou associação de riscos significativos quanto o acesso de gatos em depósitos, uma vez que o intervalo de confiança não foi significativo. Este dado está de acordo com outros trabalhos, como Valença et al. (2011), em granjas de suínos e Pereira et al. (2012), em propriedades de ovinos e caprinos, os quais também demonstraram que não houve esta associação à infecção pelo T. gondii acesso de gatos em locais de armazenamento de alimentos. Conforme Cademartori et al. (2008), a maioria dos estudos epidemiológicos já realizados não são uniformes quanto à associação entre a infecção por T. gondii e o convívio com gatos, relatando que também não foi constatada essa associação em trabalho realizado com gestantes em Pelotas/RS.

Quando pesquisada a relação dos animais de produção e a toxoplasmose, trabalhos afirmam que os mesmos podem representar um verdadeiro risco para a transmissão da toxoplasmose, seja direta ou indiretamente (Samra et al. 2007, Cenci Goga 2011). Carnes de suínos, ovinos e caprinos abrigam um grande número de cistos teciduais e que a carne de bovinos e búfalos raramente contém cistos, no entanto, em algumas regiões, mais de $90 \%$ de bovinos são soropositivos para T. gondii (Dubey \& Jones 2008). Na maioria das propriedades pesquisadas em $66(89,1 \%)$, pelo menos uma espécie animal é abatida para consumo próprio, sendo que 51 destas apresentaram galinhas positivas. Ou seja, segundo teste Exato de Fischer (com 95\% de confiança $(p=0,027)$ ), propriedades em que é realizado o abate de animais para consumo, a frequência de soropositividade em galinhas é maior. Conforme Guo et al. (2015) em suínos e outros animais criados extensivamente, a probabilidade de infecção da carne e produtos processados (embutidos) é maior que em animais criados de forma intensiva. Considerando essa afirmação, em todas as propriedades em que os animais eram abatidos para o consumo, apresentava-se risco potencial de infecção, a partir da carne. Embora as variáveis de abate não tenham apresentado associação significativa ao T. gondii neste estudo, não se descarta a importância desta atividade, uma vez que o elevado abate de galinhas nas propriedades pode ser fonte de infecção para felinos, já que as vísceras, quando são descartadas inadequadamente, podem ficar expostas à ingestão por esses animais.

A variável água de mina, para abastecimento animal, pode ser destacada tendo em vista à longa sobrevivência dos oocitos de T.gondii no ambiente. Se comparada às demais variáveis de abastecimento, a água de mina fica mais exposta à contaminação por oocistos, facilitada principalmente pelo carreamento dos mesmos através da água da chuva. A contaminação da água com oocistos de T. gondii, pode ser considerada tão importante quanto à contaminação de alimentos como fonte de infecção (Cenci Goga et al. 2013). Casos como o de Santa Isabel do Ivaí, em que ocorreu um surto de toxoplasmose em 2001, em virtude da contaminação de um reservatório de água da cidade por oocistos, demonstram o alto risco do acesso de gatos nestes locais (Dubey et al. 2004). Somado a isto, apenas nas propriedades abastecidas por água de via pública, as pessoas e animais ingeriam água tratada. Nas demais, onde se fazia o uso de água de artesiano, de poço convencional ou de mina, a mesma não recebia nenhum tipo de tratamento, nem mesmo processo de filtração, podendo ter 
um potencial risco para humanos e animais. Isto fortalece a importância do tratamento da água para minimizar os riscos de infecção, principalmente quando se tem apenas fonte de água de mina disponível, já que a mesma tem um potencial de contaminação facilitado.

Diante da variedade de fatores epidemiológicos relacionados, a compreensão das principais vias de transmissão horizontal é de extrema importância, tornando-se um desafio para o desenvolvimento de práticas sanitárias eficientes para a prevenção da toxoplasmose em humanos e animais. A partir dos resultados observados neste estudo podemos reafirmar a importância das galinhas domésticas como hospedeiros intermediários de T. gondii, visto a grande prevalência encontrada. Estas aves podem servir como uma fonte de infecção para felídeos e outros hospedeiros intermediários nas diferentes propriedades rurais pesquisadas, uma vez que em um grande número delas há o abate desses animais para o consumo, podendo ser consideradas um importante fator de risco para toxoplasmose. Com relação à contaminação ambiental por T. gondii podemos inferir que os oocistos encontram-se amplamente distribuídos na zona rural de Santa Maria. Diante disso, ressalta-se a necessidade de implantação de programas educativos com medidas de prevenção e controle da toxoplasmose, gerando conhecimento para a população com relação aos fatores de risco a doença.

Comitê de Ética e Biossegurança.- 0 projeto foi aprovado pelo Comitê de Ética para uso animal protocolo (CEUA-UFSM 049/2012) e para uso humano (CEP-UFSM parecer $\mathrm{n}$ ํ 1.055.848)

Agradecimentos.- À CAPES pelo financiamento do projeto e concessão da bolsa. À professora Dra. Maria Cecília Venturini do Laboratorio de Immunoparasitología da Universidad Nacional de La Plata pelo apoio inicial da condução deste trabalho.

\section{REFERÊNCIAS}

Bahia-Oliveira L.M., Jones J.L., Azevedo-Silva J., Alves C.C., Orefice F. \& Addiss D.G. 2003. Highly endemic, waterborne toxoplasmosis in north Rio de Janeiro state, Brazil. Emerg. Infect. Dis. 9(1):55-62. <http://dx.doi.org/10.3201/ eid0901.020160>

Brandão G.P., Ferreira A.M., Melo M.N. \& Vitor R.W.A. 2006. Characterization of Toxoplasma gondii from domestic animals from Minas Gerais, Brazil. Parasite 13(2):143-149. <http://dx.doi.org/10.1051/parasite/2006132143> $<$ PMid:16800123>

Cademartori B.G., Farias N.A.R. \& Brod C.S. 2008. Soroprevalência e fatores de risco à infecção por Toxoplasma gondii em gestantes de Pelotas, Sul do Brasil. Revta Panam. Infectol. 10:30-35.

Casartelli-Alves L.C., Ferreira L.C., Vicente R.T., Millar P.R., Oliveira R.V.C., Amendoeira M.R.R., Schubach T.M.P. \& Menezes R.C. 2012. Prevalência da infecção por Toxoplasma gondii em galinhas criadas extensivamente em Rio Bonito, Rio de Janeiro. Arq. Bras. Med. Vet. Zootec. 64(5):1398-1401. <http://dx.doi.org/10.1590/S0102-09352012000500042>

Casartelli-Alves L., Boechat V.C., Macedo-Couto R., Ferreira L.C., Nicolau J.L., Neves L.B., Millar P.R., Vicente R.T., Oliveira R.V., Muniz A.G., Bonna I.C., Amendoeira M.R., Silva R.C., Langoni H., Schubach T.M. \& Menezes R.C. 2014. Sensitivity and specificity of serological tests, histopathology and immunohistochemistry for detection of Toxoplasma gondii infection in domestic chickens. Vet. Parasitol. 204(3/4):346-351. <http://dx.doi. org/10.1016/j.vetpar.2014.05.039><PMid:24953750>
Cenci-Goga B.T., Rossitto P.V., Sechi P., McCrindle C.M. \& Cullor J.S. 2011. Toxoplasma in animals, food and humans: an old parasite of new concern. Foodborne Pathog. Dis. 8(7):751-762. <PMid:21486145>

Cenci-Goga B.T., Ciampelli A., Sechi P., Veronesi F., Moretta I., Cambiotti V. \& Thompson P.N. 2013. Seroprevalence and risk factors for Toxoplasma gondii in sheep in Grosseto district, Tuscany, Italy. BMC Vet. Res. 9:25. <http://dx.doi.org/10.1186/1746-6148-9-25><PMid:23391299>

Dubey J.P. 1998. Toxoplasma gondii oocyst survival under defined temperatures. J. Parasitol. 84(4):862-865. <http://dx.doi.org/10.2307/3284606> <PMid:9714227>

Dubey J.P. 2002. A review of toxoplasmosis in wild birds. Vet. Parasitol. 106(2):121-153. <http://dx.doi.org/10.1016/S0304-4017(02)00034-1> <PMid:12031816>

Dubey J.P. \& Jones J.L. 2008. Toxoplasma gondii infection in humans and animals in the United States. Int. J. Parasit. 38(11):1257-1278. <PMid:18508057>

Dubey J.P., Laurin E. \& Kwowk O.C. 2016. Validation of the modified agglutination test for the detection of Toxoplasma gondii in free-range chickens by using cat and mouse bioassay. Parasitol. 143(3):314-319. <http://dx.doi.org/10.1017/S0031182015001316><PMid:26625933>

Dubey J.P., Lago E.G., Gennari S.M., Su C. \& Jones J.L. 2012. Toxoplasmosis in humans and animals in Brazil: high prevalence, high burden of disease, and epidemiology. Parasitology 139(11):1375-1424. <http://dx.doi. org/10.1017/S0031182012000765><PMid:22776427>

Dubey J.P., Gennari S.M., Labruna M.B., Camargo L.M.A., Vianna M.C.B., Marcet P.L. \& Lehmann T. 2006. Characterization of Toxoplasma gondii isolates in free-range chickens from Amazon, Brazil. J. Parasitol. 92(1):36-40.<http:// dx.doi.org/10.1645/GE-655R.1><PMid:16629312>

Dubey J.P., Sundar N., Gennari S.M., Minervino A.H., Farias N.A., Ruas J.L., Santos T.R., Cavalcante G.T., Kwok O.C. \& Su C. 2007. Biologic and genetic comparison of Toxoplasma gondii isolates in free-range chickens from the northern Para state and the southern state Rio Grande do Sul, Brazil, revealed highly diverse and distinct parasite populations. Vet. Parasitol. 143(2):182-188. <http://dx.doi.org/10.1016/j.vetpar.2006.08.024> <PMid:16982151>

Dubey J.P., Navarro I.T., Sreekumar C., Dahl E., Freire R.L., Kawabata H.H., Vianna M.C., Kwok O.C., Shen S.K., Thulliez P. \& Lehmann T. 2004. Toxoplasma gondii infections in cats from Paraná, Brazil: seroprevalence, tissue distribution, and biologic and genetic characterization of isolates. J. Parasitol. 90(4):721726. <http://dx.doi.org/10.1645/GE-382R > <PMid:15359466>

Dubey J.P. 2010a. Toxoplasma gondii infections in chickens (Gallus domesticus): prevalence, clinical disease, diagnosis and public health significance. Zoonoses Public Health 57(1):60-73. <http://dx.doi. org/10.1111/j.1863-2378.2009.01274.x><PMid:19744305>

Dubey J.P., Rajendran C., Costa D.G.C., Ferreira L.R., Kwok O.C.H., Qu D., Su C., Marvulo M.F.V., Alves L.C., Mota R.A. \& Silva J.C.R. 2010b. New Toxoplasma gondii genotypes isolated from free-range chickens from the Fernando de Noronha, Brazil: unexpected findings. J. Parasitol. 96(4):709-712.<http:// dx.doi.org/10.1645/GE-2425.1> <PMid:20486738>

Dzitko K., Staczek P., Gatkowska J. \& Dlugonska H. 2006. Toxoplasma gondii: serological recognition of reinfection. Experimental Parasitol. 112(2):134137. <http://dx.doi.org/10.1016/j.exppara.2005.09.010><PMid:16289467>

Garcia J.L., Navarro I.T., Ogawa L. \& Marana E.R.M. 2000. Soroprevalência do Toxoplasma gondii em galinhas (Gallus gallus domesticus) de criações domésticas, oriundas de propriedades rurais do norte do Paraná, Brasil. Ciência Rural 30(1):123-127. <http://dx.doi.org/10.1590/S010384782000000100020>

Guo M., Dubey J.P., Hill D., Buchanan R.L., Gamble H.R., Jones J.L. \& Pradhan A.K. 2015. Prevalence and risk factors for toxoplasma gondii infection in meat animals and meat products destined for human consumption. J. Food Protect. 78(2):457-476. <http://dx.doi.org/10.4315/0362-028X. JFP-14-328><PMid:25710166> 
Larsson C.D. 1989. Diagnóstico laboratorial da Toxoplasmose: reações utilizadas e interpretação clínica. Cães e Gatos 4(24):5-11.

Luzon M., Miro G. \& Gozalo A. 1997. Epidemiologia: Toxoplasmosis. Revta Ovis, Tratado de Patologia y Produccion Ovina 52:19-32.

Moré G., Basso W., Bacigalupe D., Venturini M.C. \& Venturini L. 2008. Diagnosis of Sarcocystis cruzi, Neospora caninum, and Toxoplasma gondii infections in cattle. Parasitol. Res. 102(4):671-675. <http://dx.doi.org/10.1007/ s00436-007-0810-6><PMid:18066600>

Oliveira L.N., Costa Junior L.M., Melo C.F., Ramos Silva J.C., Bevilaqua C.M., Azevedo S.S., Muradian V., Araújo D.A., Dubey J.P. \& Gennari S.M. 2009. Toxoplasma gondii isolates from free-range chickens from the Northeast region of Brazil. J. Parasitol. 95(1):235-237. <http://dx.doi.org/10.1645/ GE-1730.1><PMid:18578589>

Pereira M.F., Peixoto R.M. \& Langoni H. 2012. Fatores de risco associados à infecção por Toxoplasma gondii em ovinos e caprinos no estado de Pernambuco. Pesq. Vet. Bras. 32(2):140-146. <http://dx.doi.org/10.1590/ S0100-36X2012000200009>
Ruiz A. \& Frenkel J.K. 1980. Intermediate and transport hosts of Toxoplasma gondii in Costa Rica. Am. Soc. Trop. Med. Hyg. 29(6):1161-1166. <http:// dx.doi.org/10.4269/ajtmh.1980.29.1161><PMid:7446807>

Samra N.A., McCrindle C.M.E., Penzhorn B.L. \& Cenci-Goga B. 2007. Seroprevalence of toxoplasmosis in sheep in South Africa. J. South Afr. Vet. Assoc. 78(3):116-120. <PMid:18237032>

Tenter A.M., Heckeroth A.R. \& Weiss L.M. 2000. Toxoplasma gondii: from animals to humans. Int. J. Parasitol. 30(12/13):1217-1258. <https://doi. org/10.1016/S0020-7519(00)00124-7><PMid:11113252>

Valença R.M.B., Mota R.A., Anderlini G.A., Faria E.B., Cavalcanti E.F.S.T.F., Albuquerque P.P.F., Neto O.L.S. \& Guerra M.M.P. 2011. Prevalência e fatores de risco associados à infecção por Toxoplasma gondii em granjas suinícolas tecnificadas no Estado de Alagoas. Pesq. Vet. Bras. 31(2):121-126. <http://dx.doi.org/10.1590/S0100-736X2011000200005>

Wastling J.M., Harkins D., Maley S., Innes E., Panton W., Thomson K. \& Buxton D. 1995 Kinetics of the local and systemic antibody response to primary and secondary infection with S48 Toxoplasma gondii in sheep. J. Comp. Pathol. 112(1):53-62. <http://dx.doi.org/10.1016/S0021-9975(05)80089-1><PMid:7722008> 